
3 Research Square
Preprints are preliminary reports that have not undergone peer review.
They should not be considered conclusive, used to inform clinical practice,
or referenced by the media as validated information.

\title{
Dosimetric comparison and TCP-NTCP modelling for lung, heart, left anterior descending and right coronary artery in left sided breast cancer conventional and hypofractionated radiotherapy
}

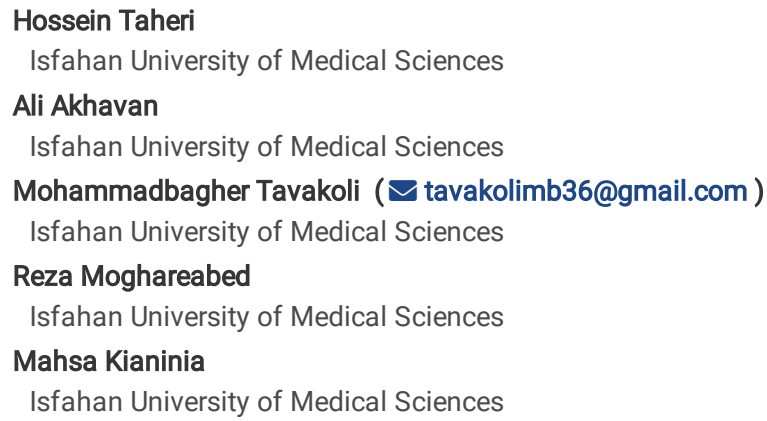




\section{Abstract}

Background

The aim of this study was to evaluate the dose distribution, and also tumor control probability (TCP) and normal tissue complications probability (NTCP) models of left sided breast cancer females for 3D-CRT, 6 and 9 fields IMRT and hypofractionated tangential plans.

Methods

Sixty left sided breast cancer females were included in this study. CT simulation images of the patients were imported on the treatment planning software (TiGRT, LinaTech, China), and the tangential treatment plans of the mentioned methods were done for each patient. The dosimetric evaluation, and TCP-NTCP models of stated modalities were done using Poisson Linear-Quadatric (PLQ) and Lyman-Kutcher-Burman (LKB) models on the MATLAB and R softwares.

Results

The mean $( \pm S D)$ dose to ipsilateral lung, heart, LAD and RCA with/without internal mammary fields for 6FIMRT was lower compared to other modalities. Furthermore, $\mathrm{V}_{20 \mathrm{~Gy}}$ for Ipsilateral lung and $\mathrm{V}_{25 \mathrm{~Gy}}$ for heart, LAD and RCA of 6FIMRT was lower than other methods. In addition, the PTV dose coverage was higher for 9FIMRT and hypofractionated RT, while it may be lower for 3D-CRT among the studied methods. Although TCP values of 9 and 6 fieds and hypofractionated was not significantly different, the TCPs of them were higher compared to 3D-CRT. However, the NTCP for ipsilateral lung, heart, LAD and RCA of 6FIMRT was lower than others.

Conclusion

6FIMRT is suitable choice for RT of breast cancer patients compared to other mentioned modalities, as a result of providing adequate PTV dose coverage and TCP, and also lower imposed dose and NTCP for OARs. Hypofractionated RT is a good alternative to reduce treatment time for the breast cancer patients.

Trial registration

This study was approved by the ethical board of Isfahan University of Medical Sciences, Isfahan, Iran (IR.MUI.MED.REC.1399.677).

\section{Background}

For high risk breast cancer patients, breast conserving surgery that followed by adjuvant radiotherapy (RT) is taken into account as the most common treatment method (1-3). Literatures have shown that, the number of breast cancer females have been increased during the recent two decades around the world (4-6). In this regard, a number of studies have shown that adjuvant RT of the mentioned patients may improve local control and survival of them (6-9). The RT of the patients is commonly done using two photon tangential beams, which irradiate the whole breast and the anterior part of thoracic volume (6, $10-$ 11). A large number of studies have been demonstrated that, RT of the patients may increase the normal tissue complications including, lung secondary cancer, and also heart morbidity and mortality which resulted from imposed radiation dose to cardiovascular structures (7,12-17). Zablotska and Neugut have reported that, the imposed radiation dose to lungs may pose to a moderate rise in complications for the mentioned organ (12). There are different RT modalities such as 3D-CRT and IMRT tangential plans which are commonly applied to treat mentioned patients. A host of studies have discussed about the imposed dose to the organ at risks (OARs) using different modalities (17-20). Aznar et al. have found that, evaluation of the dose to the whole heart, arch and whole LAD is a suitable approach, because calculation of radiation dose to only one of these structures may lead to excessive imposed dose to them and also may increase the risk of cardiac complications (17). Zhang et al. have found that, IMRT may provide higher target dose coverage and dose uniformity compared to conformal RT for the left sided breast cancer patients (19).

Although many studies have been demonstrated that using tangential beams may provide enough dose distribution in the target volumes for the RT of the whole breast compared to other methods, data about depth dose distribution of above stated tangential methods and their complications on the normal tissues such as ipsilateral lung, heart and cardiovascular structures including, LAD, and also RCA are scarce. According to reading different studies and literatures, it would seem that, there is not an exact advantages and disadvantages of 3D-CRT, IMRT and hypofractionated RT with regard to their adverse effects to coronary arteries such as LAD and RCA.

Therefore, this work aimed to evaluate the dose distribution, and also radiobiological models including tumor control probability (TCP) and normal tissue complications probability (NTCP) for target volume and normal tissues including ipsilateral lung, heart and cardiovascular structures namely, LAD and RCA in the above mentioned tangential plans.

\section{Methods}

The study protocol of this work was approved by the ethical board of Isfahan University of Medical Sciences, Isfahan, Iran (IR.MUI.MED.REC.1399.677) according to the 1975 Helsinki declaration and its revision in 2000.

Sixty left sided breast cancer patients who underwent RT in Sayed-Al Shohada hospital, Isfahan, Iran were included in this study. CT simulation images of the patients were imported on the treatment planning software (TiGRT, LinaTech, China), and the treatment plans of studied modalities including; 3D-CRT, 6fields (6FIMRT) and also 9fields IMRT (9FIMRT) inverse planning, and also hypofractionated IMRT for each patient were done by three independent expert radiation oncologist using the mentioned TPS. The applied TPS was commissioned according to a Siemens Primus linac measured data (Siemens, Germany).

Treatment planning of the patients was performed using $6 \mathrm{MV}$ photon beams of the stated linac according to patient's geometry and chest wall sizes. In this

Page 2/8 
study, the chest wall surface, three levels of axilla and supraclavicular lymph nodes were defined as CTV. Furthermore, the planning target volume (PTV) was defined with $1 \mathrm{~cm}$ margin around the CTV. Moreover, the OARs were ipsilateral lung, heart, LAD and also RCA. The prescribed dose for the 3D-CRT and IMRT inverse plans was $2 \mathrm{~Gy}$ per fraction (25 fraction) for PTV with a total dose of $50 \mathrm{~Gy}$, while the dose for the hypofractionated RT was $2.3 \mathrm{~Gy}$ per fraction (20 fraction) with the total prescribed dose of $46 \mathrm{~Gy}$. The source to surface distance (SSD) was $100 \mathrm{~cm}$, and the above stated plans was done in SSD set up for each patients. The treatment plan was done based on RTOG protocol and the whole chest wall was irradiated by $6 \mathrm{MV}$ tangential photon beams. Furthermore, the mean imposed radiation dose to the OARs was measured with and without internal mammary nodes for each patient. In addition, the volume of the heart, $\mathrm{LAD}$ and RCA irradiating more than $25 \mathrm{~Gy}\left(\mathrm{~V}_{25 \mathrm{~Gy}}\right)$, and also the volume of ipsilateral lung exposing more than $20 \mathrm{~Gy}\left(\mathrm{~V}_{20 \mathrm{~Gy}}\right)$ were compared for each patient among the mentioned modalities. Moreover, the maximum heart distance (MHD) was measured using beam eye view (BEV).

\section{TCP_NTCP modelling}

The TCP and NTCP for each of the above stated situations were calculated using DVH data. In this study, the Poisson Linear-Quadatric (PLQ) model was employed for estimating the TCP according the following below (equation 1) $(21,22)$ :

$$
T C P=[-N \cdot p s(D)]
$$

Where, $N$ is the initial number of tumoral cells, and the $p_{\mathrm{s}}(D)$ is the cell survival fraction after a dose $D$.

For NTCP calculation, Lyman-Kutcher-Burman (LKB) model were used according the equation $2(23,24)$.

$$
N T C P=\frac{1}{\sqrt{2 \pi}} \int_{-\infty}^{t} \exp \left(-\frac{u^{2}}{2}\right) d u
$$

Where, the $t$ is calculated based on the following formula (equation 3):

$$
t=\frac{E U D_{a}-D_{50}}{D_{50} \cdot m}
$$

In the above equation, " $\mathrm{m}$ " is the maximum inverse slope of dose-response curve, EUD is the equivalent uniform dose of the mentioned OARs (25-27), and also $D_{50}$ is the total imposed radiation dose to the studied normal tissues that may lead to force $50 \%$ complication to the organ.

\section{MATLAB Program \& R environment}

The generated DVHs were evaluated and the TCP-NTCP models were created in MATLAB and R programs. The $\alpha / \beta$ ratio of OARs, slope of dose-response curve of $50 \%$, dose tolerance of $50 \%$ and $\mathrm{m}$ were determined based on PLQ- LKB models in the mentioned programs.

\section{Results}

Figure 1, illustrates the generated DVHs for the 3D-CRT and IMRT inverse plans.

Table 1, indicates the mean ( \pm SD) dose to PTV and also imposed radiation dose to the OARs among the studied methods. Table 2, gives a comparison between tumor control and OARs complications probabilities for the patients. PTV coverage of 9FIMRT and hypofractionated IMRT (95\%) was higher than the 6 fields (94\%) and 3D-CRT (92\%). 
Table 1

The imposed radiation dose to OARs among 3D-CRT, 6 and 9fields IMRT inverse plans and hypofractionated IMRT.

\begin{tabular}{|c|c|c|c|c|c|c|c|c|c|}
\hline & $\begin{array}{l}\text { 3D-CRT } \\
\text { (with/without } \\
\text { internal } \\
\text { mammary } \\
\text { fields) }\end{array}$ & $\begin{array}{l}\text { 6fiels } \\
\text { IMRT } \\
\text { inverse } \\
\text { planning } \\
\text { ( } \\
\text { with/without } \\
\text { internal } \\
\text { mammary } \\
\text { fields) }\end{array}$ & $\begin{array}{l}\text { 9fields } \\
\text { IMRT inverse } \\
\text { planning } \\
\text { (with/without } \\
\text { internal } \\
\text { mammary } \\
\text { fields) }\end{array}$ & $\begin{array}{l}\text { Hypofractionated } \\
\text { IMRT } \\
\text { (with/without } \\
\text { internal } \\
\text { mammary fields) }\end{array}$ & $\begin{array}{l}\text { 3D-CRT } \\
\text { vs } \\
\text { 6FIMRT } \\
\text { (p } \\
\text { value) }\end{array}$ & $\begin{array}{l}\text { 3D-CRT } \\
\text { vs } \\
\text { 9FIMRT } \\
\text { (p } \\
\text { value) }\end{array}$ & $\begin{array}{l}\text { 3D-CRT vs } \\
\text { Hypofractionated } \\
\text { IMRT } \\
\text { (p value) }\end{array}$ & $\begin{array}{l}6 \mathrm{~F} \text { vs } \\
9 \mathrm{~F} \\
\text { IMRT } \\
\text { (p } \\
\text { value) }\end{array}$ & $\begin{array}{l}\text { 6F vs } \\
\text { Hypofractionated } \\
\text { IMRT (p value) }\end{array}$ \\
\hline $\begin{array}{l}\text { PTV } \\
\text { Coverage } \\
(\%)\end{array}$ & 92 & 94 & 95 & 95 & & & & & \\
\hline \multicolumn{10}{|l|}{$\begin{array}{l}\text { Ipsilateral } \\
\text { lung }\end{array}$} \\
\hline $\begin{array}{l}\text { Mean } \\
\text { Dose }\end{array}$ & $\begin{array}{l}12.62 \pm 0.56 / \\
12.21 \pm 0.43\end{array}$ & $\begin{array}{l}8.32 \pm 1.03 / \\
8.04 \pm 0.87\end{array}$ & $\begin{array}{l}10.57 \pm 1.01 \\
/ 9.91 \pm 0.74\end{array}$ & $\begin{array}{l}10.23 \pm 1.00 / \\
9.81 \pm 0.78\end{array}$ & $<0.005$ & $<0.005$ & $<0.005$ & $\begin{array}{l}> \\
0.005\end{array}$ & $>0.005$ \\
\hline $\begin{array}{l}\text { Maximum } \\
\text { Dose }\end{array}$ & $58.77 / 54.46$ & $\begin{array}{l}31.58 \\
/ 27.29\end{array}$ & 37.64 / 32.46 & 36.25 / 31.73 & $<0.005$ & $<0.005$ & $<0.005$ & ${ }_{0.005}$ & $>0.005$ \\
\hline $\begin{array}{l}\text { Minimum } \\
\text { Dose }\end{array}$ & $42.21 / 41.08$ & $\begin{array}{l}29.37 / \\
27.34\end{array}$ & $34.86 / 31.46$ & $33.67 / 31.62$ & $<0.005$ & $<0.005$ & $<0.005$ & $>0.005$ & $>0.005$ \\
\hline $\mathrm{V}_{20 G y}(\%)$ & $\begin{array}{l}10.08 \pm 1.07 \\
/ 12.23 \pm 1.93\end{array}$ & $\begin{array}{l}7.43 \pm 1.14 / \\
9.46 \pm 1.26\end{array}$ & $\begin{array}{l}8.15 \pm 1.38 / \\
10.48 \pm 1.41\end{array}$ & $\begin{array}{l}8.07 \pm 1.23 / \\
10.31 \pm 1.22\end{array}$ & $<0.005$ & $<0.005$ & $<0.005$ & $\overrightarrow{0.005}$ & $>0.005$ \\
\hline \multicolumn{10}{|l|}{ Heart } \\
\hline $\begin{array}{l}\text { Mean } \\
\text { Dose }\end{array}$ & $\begin{array}{l}4.95 \pm 0.86 \\
/ 2.26 \pm 0.72\end{array}$ & $\begin{array}{l}2.53 \pm 1.18 \\
/ 2.36 \pm 0.69\end{array}$ & $\begin{array}{l}3.62 \pm 1.18 / \\
4.51 \pm 0.84\end{array}$ & $\begin{array}{l}3.37 \pm 1.07 / / \\
4.26 \pm 0.84\end{array}$ & $<0.005$ & $<0.005$ & $<0.005$ & $\overrightarrow{0} .005$ & $>0.005$ \\
\hline $\begin{array}{l}\text { Maximum } \\
\text { Dose }\end{array}$ & $55.04 / 48.02$ & $\begin{array}{l}44.24 / \\
41.78\end{array}$ & $47.56 / 43.61$ & $47.32 / 43.16$ & $<0.005$ & $<0.005$ & $<0.005$ & 0.005 & $>0.005$ \\
\hline $\begin{array}{l}\text { Minimum } \\
\text { Dose }\end{array}$ & $0.22 / 0.19$ & $0.20 / 0.18$ & $0.20 / 0.19$ & $0.20 / 0.17$ & $>0.005$ & $>0.005$ & $<0.005$ & ${ }_{0.005}$ & $>0.005$ \\
\hline$V_{25 G y}(\%)$ & $\begin{array}{l}18.51 \pm 2.14 \\
/ 21.43 \pm \\
1.87\end{array}$ & $\begin{array}{l}13.76 \pm \\
1.04 / 22.07 \\
\pm 1.27\end{array}$ & $\begin{array}{l}14.29 \pm 1.37 \\
/ 22.98 \pm \\
0.28\end{array}$ & $\begin{array}{l}14.03 \pm 1.16 / \\
21.47 \pm 0.23\end{array}$ & $<0.005$ & $<0.005$ & $<0.005$ & $\overrightarrow{0.005}$ & $>0.005$ \\
\hline \multicolumn{10}{|l|}{ LAD } \\
\hline $\begin{array}{l}\text { Mean } \\
\text { Dose }\end{array}$ & $\begin{array}{l}6.79 \pm 1.25 \\
/ 4.12 \pm 0.87\end{array}$ & $\begin{array}{l}3.14 \pm 1.37 / / \\
3.93 \pm 0.95\end{array}$ & $\begin{array}{l}5.46 \pm 1.83 \\
/ 4.38 \pm 1.04\end{array}$ & $\begin{array}{l}5.24 \pm 1.15 / 4.24 \\
\pm 0.97\end{array}$ & $<0.005$ & $<0.005$ & $<0.005$ & $\begin{array}{l}> \\
0.005\end{array}$ & $>0.005$ \\
\hline $\begin{array}{l}\text { Maximum } \\
\text { Dose }\end{array}$ & $56.21 / 52.14$ & $\begin{array}{l}45.23 / \\
49.61\end{array}$ & $47.65 / 50.19$ & $46.17 / 50.02$ & $<0.005$ & $<0.005$ & $<0.005$ & $\overrightarrow{0.005}$ & $>0.005$ \\
\hline $\begin{array}{l}\text { Minimum } \\
\text { Dose }\end{array}$ & $1.26 / 1.15$ & $0.76 / 0.50$ & $1.08 / 0.98$ & $1.01 / 0.89$ & $>0.005$ & $>0.005$ & $<0.005$ & ${ }_{0.005}$ & $>0.005$ \\
\hline $\mathrm{V}_{25 \mathrm{~Gy}}(\%)$ & $\begin{array}{l}19.27 \pm 1.38 \\
/ 22.56 \pm \\
2.37\end{array}$ & $\begin{array}{l}15.75 \pm 1.24 \\
/ 17.63 \pm \\
2.41\end{array}$ & $\begin{array}{l}17.27 \pm 0.64 \\
/ 18.56 \pm \\
1.51\end{array}$ & $\begin{array}{l}16.97 \pm 0.32 / \\
18.23 \pm 1.27\end{array}$ & $<0.005$ & $<0.005$ & $<0.005$ & $>_{0.005}$ & $>0.005$ \\
\hline \multicolumn{10}{|l|}{ RCA } \\
\hline $\begin{array}{l}\text { Mean } \\
\text { Dose }\end{array}$ & $\begin{array}{l}1.17 \pm 0.06 \\
/ 0.73 \pm 0.18\end{array}$ & $\begin{array}{l}0.71 \pm 0.23 / \\
0.58 \pm 0.27\end{array}$ & $\begin{array}{l}0.92 \pm 0.14 / \\
0.89 \pm 0.11\end{array}$ & $\begin{array}{l}0.89 \pm 0.10 / 0.82 \\
\pm 0.11\end{array}$ & $<0.005$ & $<0.005$ & $<0.005$ & ${ }_{0.005}$ & $>0.005$ \\
\hline $\begin{array}{l}\text { Maximum } \\
\text { Dose }\end{array}$ & 43.18 / 35.63 & $\begin{array}{l}38.64 / \\
37.69\end{array}$ & 40.94 / 39.77 & 40.05 / 39.21 & $<0.005$ & $<0.005$ & $<0.005$ & $\overrightarrow{0.005}$ & $>0.005$ \\
\hline $\begin{array}{l}\text { Minimum } \\
\text { Dose }\end{array}$ & $0.15 / 0.11$ & $0.10 / 0.10$ & $0.11 / 0.11$ & $0.09 / 0.08$ & $<0.005$ & $<0.005$ & $<0.005$ & 0.005 & $>0.005$ \\
\hline $\mathrm{V}_{25 \mathrm{~Gy}}(\%)$ & $\begin{array}{l}13.42 \pm 1.59 \\
/ 16.74 \pm \\
1.32\end{array}$ & $\begin{array}{l}10.53 \pm 1.24 \\
/ 14.36 \pm \\
1.57\end{array}$ & $\begin{array}{l}10.79 \pm 1.64 \\
/ 14.98 \pm \\
1.06\end{array}$ & $\begin{array}{l}10.34 \pm 1.16 / \\
14.24 \pm 1.11\end{array}$ & $>0.005$ & $>0.005$ & $<0.005$ & $\overrightarrow{0}_{0.005}$ & $>0.005$ \\
\hline \multicolumn{10}{|l|}{ MHD } \\
\hline $\begin{array}{l}\text { Mean } \\
\text { (Range) }\end{array}$ & $\begin{array}{l}1.26(0.9- \\
1.43)\end{array}$ & $\begin{array}{l}1.26(0.9- \\
1.43)\end{array}$ & $\begin{array}{l}1.26(0.9- \\
1.43)\end{array}$ & $1.26(0.9-1.43)$ & & & & & \\
\hline
\end{tabular}


Table 2

The TCP and NTCP values among the studied modalities.

\begin{tabular}{|c|c|c|c|c|c|c|c|c|}
\hline & $\begin{array}{l}\text { 3D-CRT } \\
\text { (with/ without } \\
\text { internal } \\
\text { mammary } \\
\text { fields) }\end{array}$ & & $\begin{array}{l}6 F \\
\text { IMRT inverse } \\
\text { planning } \\
\text { (with/without } \\
\text { internal } \\
\text { mammary fields) }\end{array}$ & & $\begin{array}{l}9 \mathrm{~F} \\
\text { IMRT inverse } \\
\text { planning } \\
\text { (with/without } \\
\text { internal } \\
\text { mammary } \\
\text { fields) }\end{array}$ & & $\begin{array}{l}\text { Hypofractionated } \\
\text { IMRT } \\
\text { (with/without } \\
\text { internal } \\
\text { mammary fields) }\end{array}$ & \\
\hline & MATLAB & $\begin{array}{l}\mathbf{R} \\
\text { environment }\end{array}$ & MATLAB & $\begin{array}{l}\mathbf{R} \\
\text { environment }\end{array}$ & MATLAB & $\begin{array}{l}\mathrm{R} \\
\text { environment }\end{array}$ & MATLAB & $\begin{array}{l}\text { R } \\
\text { environment }\end{array}$ \\
\hline $\begin{array}{l}\text { TCP } \\
(\%)\end{array}$ & & & & & & & & \\
\hline $\begin{array}{l}\text { Chest } \\
\text { Wall }\end{array}$ & $87 / 86$ & $86 / 85$ & $91 / 90$ & $91 / 90$ & $92 / 90$ & $92 / 90$ & $92 / 90$ & $92 / 90$ \\
\hline Axilla & $90 / 90$ & $91 / 91$ & $92 / 92$ & $92 / 92$ & $92 / 92$ & $93 / 92$ & $92 / 92$ & $93 / 92$ \\
\hline $\begin{array}{l}\text { Supra- } \\
\text { Clavicu } \\
\text { Lar } \\
\text { Nodes }\end{array}$ & $94 / 94$ & $94 / 94$ & $94 / 94$ & $94 / 94$ & $94 / 94$ & $94 / 94$ & $94 / 94$ & $94 / 93$ \\
\hline $\begin{array}{l}\text { Internal } \\
\text { Mammary } \\
\text { Nodes }\end{array}$ & $93 / 86$ & $93 / 85$ & $95 / 89$ & $96 / 90$ & $96 / 91$ & $96 / 90$ & $96 / 91$ & $96 / 90$ \\
\hline $\begin{array}{l}\text { NTCP } \\
(\%)\end{array}$ & & & & & & & & \\
\hline $\begin{array}{l}\text { Ipsilateral } \\
\text { Lung }\end{array}$ & $8 / 6$ & $8 / 6$ & $5 / 4$ & $5 / 4$ & $6 / 5$ & $6 / 5$ & $6 / 5$ & $6 / 5$ \\
\hline Heart & $4 / 3$ & $5 / 3$ & $2 / 1$ & $2 / 1$ & $3 / 2$ & $2 / 1$ & $3 / 2$ & $2 / 1$ \\
\hline LAD & $6 / 5$ & $6 / 5$ & $3 / 2$ & $3 / 2$ & $4 / 3$ & $4 / 3$ & $4 / 3$ & $4 / 3$ \\
\hline RCA & $1 / 0.7$ & $2 / 1.5$ & $0.8 / 0.4$ & $0.7 / 0.5$ & $2 / 1.3$ & $2 / 1.4$ & $2 / 1.3$ & $2 / 1.4$ \\
\hline
\end{tabular}

The mean ( \pm SD) imposed radiation dose (with/ without internal mammary fields) to Ipsilateral lung, heart, LAD and RCA was $12.62 \pm 0.56 / 12.21 \pm 0.43,4.95$ $\pm 0.86 / 2.26 \pm 0.72,6.79 \pm 1.25 / 4.12 \pm 0.87$ and $1.17 \pm 0.06 / 0.73 \pm 0.18$ for the 3D-CRT, respectively (Table 1 ). In addition, the $V_{20 G y}$ for Ipsilateral lung, and $\mathrm{V}_{25 \mathrm{~Gy}}$ for heart, LAD and RCA (with/ without internal mammary fields) was $10.08 \pm 1.07 / 12.23 \pm 1.93,18.51 \pm 2.14 / 21.43 \pm 1.87,19.27 \pm 1.38 / 22.56 \pm 2.37$ and $13.42 \pm 1.59$ / $16.74 \pm 1.32$ percent for 3D-CRT, respectively. Table 2 illustrates, the TCP models which were gained using MATLAB program for the target volume including the chest wall surface, three levels of axilla, supraclavicular and internal mammary lymph nodes (with/ without internal mammary fields) were 87 /86, 90/90, 94/94 and 93/86 percent, respectively. However, the TCP values of R software were 86/85, 91/91, 94/94 and 93/85 percent, respectively for the stated target volumes. The NTCP (with/ without internal mammary fields) of Ipsilateral lung, heart, LAD and RCA was $8 / 6,4 / 3,6 / 5$ and $1 / 0.7$ percent, respectively using MATLAB program. But, the NTCP of the organs which were generated from $\mathrm{R}$ software were $8 / 6,5 / 3,6 / 5$ and $2 / 1.5$ percent, respectively (Table 2).

Whereas, for the 6FIMRT, the mean ( \pm SD) imposed dose (with/ without internal mammary fields) to Ipsilateral lung, heart, LAD and RCA was $8.32 \pm 1.03 / 8.04$ $\pm 0.87,2.53 \pm 1.18 / 2.36 \pm 0.69,3.14 \pm 1.37 / 3.93 \pm 0.95$ and $0.71 \pm 0.23 / 0.58 \pm 0.27$. respectively. Furthermore, for the Ipsilateral lung the $V_{20 G y}$ was $7.43 \pm$ $1.14 / 9.46 \pm 1.26$ and the $V_{25 G y}$ for heart, LAD and RCA (with/ without internal mammary fields) was $13.76 \pm 1.04 / 22.07 \pm 1.27,15.75 \pm 1.24$ / 17.63 \pm 2.41 and $10.53 \pm 1.24$ / $14.36 \pm 1.57$ percent, respectively (Table 1). Table 2 indicates that, for 6FIMRT approach, TCP of the stated target (with/ without internal mammary fields) was 91/90, 92/92, 94/94 and 95/89 percent, respectively (MATLAB program). However, the TCP values which were obtained from R software was $91 / 90,92 / 92,94 / 94$ and $96 / 90$ percent, respectively. For the 6FIMRT, the NTCP of the Ipsilateral lung, heart, LAD and RCA was 5/4, 2/1, 3/2 and $0.8 / 0.4$ percent, respectively for the MATLAB program. According to R environment findings, the NTCP of the Ipsilateral lung, heart, LAD and RCA was $5 / 4,2 / 1$, $3 / 2$ and $0.7,0.5$ percent, respectively.

For the 9FIMRT, Table 1 also indicates that the mean ( \pm SD) imposed dose (with/ without internal mammary fields) to ipsilateral lung, heart, LAD and RCA was $10.57 \pm 1.01 / 9.91 \pm 0.74,3.62 \pm 1.18 / 4.51 \pm 0.84,5.46 \pm 1.83 / 4.38 \pm 1.04,0.92 \pm 0.14 / 0.89 \pm 0.11$, respectively. In addition, for the ipsilateral lung the $V_{20 G y}$ was $8.15 \pm 1.38 / 10.48 \pm 1.41$ and the $\mathrm{V}_{25 \mathrm{~Gy}}$ for heart, LAD and RCA (with/ without internal mammary fields) was $14.29 \pm 1.37 / 22.98 \pm 0.28,17.27 \pm 0.64$ / $18.56 \pm 1.51$ and $10.79 \pm 1.64 / 14.98 \pm 1.06$ percent, respectively. Table 2 indicates that, TCP of the stated target volumes (with/ without internal mammary 
fields) for 9FIMRT method was 92/90, 92/92, 94/94 and 96/91 percent, respectively (MATLAB program). Nevertheless, the TCP values of R software was 91/90, 92/92, 94/94 and 96/90 percent, respectively. For the 9FIMRT, the NTCP of the Ipsilateral lung, heart, LAD and RCA was 6/5, 3/2, 4/3 and 2/1.3 percent for the MATLAB program, and was $6 / 5,2 / 1,4 / 3$ and $2 / 1.4$ percent for the $\mathrm{R}$ program.

Table 1 also shows some data about hypofractionated IMRT. As can be seen, the mean ( \pm SD) imposed dose (with/ without internal mammary fields) to ipsilateral lung, heart, LAD and RCA was $10.23 \pm 1.00 / 9.81 \pm 0.78,3.37 \pm 1.07 / 4.26 \pm 0.84,5.24 \pm 1.15 / 4.24 \pm 0.97,0.89 \pm 0.10 / 0.82 \pm 0.11$, respectively. Moreover, for the hypofractionated method, the $\mathrm{V}_{20 \mathrm{~Gy}}$ for ipsilateral lung was $8.07 \pm 1.23 / 10.31 \pm 1.22$ and the $\mathrm{V}_{25 \mathrm{~Gy}}$ for heart, LAD and RCA (with/ without internal mammary fields) was $14.03 \pm 1.16 / 21.47 \pm 0.23,16.97 \pm 0.32$ / $18.23 \pm 1.27$ and $10.34 \pm 1.16 / 14.24 \pm 1.11$ percent, respectively. Table 2 illustrates the TCP of the mentioned target volumes (with/ without internal mammary fields) for the hypofractionated modality was $92 / 90,92 / 92,94 / 94$ and $96 / 91$ percent, respectively (MATLAB program). Nonetheless, the TCPs of R software was 91/90, 92/92, 94/94 and 96/90 percent, respectively. Table 2 also indicates that the NTCP of the Ipsilateral lung, heart, LAD and RCA was $6 / 5,3 / 2,4 / 3$ and $2 / 1.3$ for the MATLAB program, and was $6 / 5,2 / 1,4 / 3$ and $2 / 1.4$ for the R program (Similar to 9FIMRT).

\section{Discussion}

For female breast cancer patients, RT is taken into account as the most common treatment choice, and to the best of our knowledge tangential plans are widely applied for these patients. A number of studies have discussed about the imposed radiation dose to OARs such as ipsilateral lung, heart and LAD (1720), but it is considered that there is a limited data about the imposed radiation dose to other organs such as LAD and RCA for 3D-CRT, IMRT and hypofractionated modalities. In addition, it would seem that, data about the evaluation of TCP and NTCP models using MATLAB and R programs for the target volumes and OARs among the mentioned method are scarce. Therefore, the aim of this study was to evaluate the imposed dose and TCP-NTCP models for the target volumes and OARs including; ipsilateral lung, heart, LAD and RCA using MATLAB and R programs with and without internal mammary nodes.

Based on our findings, the mean $( \pm S D)$ imposed dose (with/ without internal mammary fields) to ipsilateral lung, heart, LAD and RCA for 3D-CRT was significantly higher compared to 6 and 9 fields IMRT inverse plans $(p<0.005)$. Table 1 illustrates that, the mean $( \pm$ SD) imposed radiation dose to the studied OARs for 6FIMRT was significantly lower than 3D-CRT $(p<0.005)$. In addition, the mean $( \pm S D)$ dose of 6FIMRT for the discussed OARs was lower compared to 9FIMRT and hypofractionated IMRT, but it was not significant $(p>0.005)$. Furthermore, the $V_{20 G y}$ for Ipsilateral lung and the $V_{25 G y}$ for heart, $L A D$ and $R C A$ of 6 and 9 fields and hypofractionated (with/ without internal mammary fields) was significantly lower compared to 3D-CRT ( $p<0.005$ ), while there were not any significant differences for the $V_{20 G y}$ of ipsilateral lung and the $V_{25 G y}$ of heart, LAD and RCA among 6 and 9 fields with hypofractionated RT ( $p>0.005$ ). Moreover, it was found that the mean ( \pm SD) imposed dose to LAD was higher compared to heart and RCA for the all studied modalities, while the imposed dose to RCA was lower than heart and LAD among the mentioned RT methods (Table 1), which is highly due to their different anatomical features. Furthermore, it is considered that the minimum dose of heart, LAD and RCA was not significantly different for the 3D-CRT, IMRT and hypofractionated RT ( $p$ > 0.005).

Our findings are in an agreement with Taylor et al. who stated that the imposed RT dose to the anterior part of heart including LAD is higher than whole heart (28). Recently, Gocer et al. have performed a dosimetric study on OARs of breast cancer patients including; heart, LAD, left circumflex coronary artery, right and left ventricles using tangential beams of 3D-CRT. In their study, they concluded that, the highest mean imposed dose was for LAD among heart and its coronary arteries for left-sided breast cancer patients (20), which is in line with our study. In addition, in their study, they have reported that the highest maximum radiation dose was for heart for left sided breast cancer patients (20). Moreover, the results of our study are similar to Rudat et al. who mentioned that the tangential IMRT plans may significantly reduce the dose-volumes of the ipsilateral lung and heart compared to tangential 3D-CRT for post mastectomy breast cancer patients (10). Aznar et al. have focused on the imposed dose to heart, arch and also whole LAD in respiration-adapted RT of leftsided breast cancers. In this study they found that, the radiation dose to arch and whole LAD was different for some of their patients, and thus it is demonstrated that the assessment of the dose to whole heart as well as to the whole LAD is crucial for the stated patients (17).

Based on Table 2, TCP models of MATLAB and R programs showed that, the TCP of the stated target volumes (with/ without internal mammary fields) for 9FIMRT and hypofractionated RT was higher than 6 fields and 3D-CRT, but it was not significant ( $p>0.005)$. Whereas, the NTCP of the Ipsilateral lung for 6FIMRT was lower compared to the 9 fields and hypofractionated RT $(p>0.005)$. Also, the NTCP for 3D-CRT was significantly higher than other methods ( $<<$ 0.005). Li et al. have found that the TCP of conventional RT and IMRT is more than $90 \%$, but the NTCP of lung for IMRT is less than conventional method (29), which is similar to our results. Furthermore, our findings showed that the NTCP of heart and its coronary arteries including LAD and RCA for 6FIMRT was lower compared to 3D-CRT, 9FIMRT and hypofractionated method. Moreover, our data showed that the hypofractionated RT may decrease the treatment time, which is in line with Li et al. who mentioned that their used hypofractionated technique may reduce the RT time for their breast cancer patients (29).

According to results of our study, 6FIMRT not only may provide suitable PTV dose coverage, but also may impose lower complication probabilities to OARs compared to 9FIMRT, hypofractionated RT and 3D-CRT. Nevertheless, hypofractionated method may be a good alternative to reduce breast cancer treatment time.

\section{Conclusion}

In this study, the dose distribution and TCP-NTCP models of 3D-CRT, 6 and 9 fields IMRT inverse plans and hypofractionated IMRT are evaluated for left sided breast cancer patients. Based on our findings, $6 \mathrm{~F}$ IMRT inverse planning is well worth treating left sided breast cancer patients, due to the enough dose coverage for PTV, suitable TCP for target volumes and lower NTCP for ipsilateral lung, heart, LAD and also RCA compared to others. However, as a result of lower treatment time for the hypofractionated IMRT, using this modality is suggested. 
According to our findings about the above discussed methods, further research about advantages and disadvantages of hypofractionated RT is proposed.

\section{Abbreviations}

CTV: Clinical target volume, PTV: Planning target volume, TCP: Tumor control probability, NTCP: Normal tissue complication probability, LAD: left anterior descending, RCA: right coronary artery

\section{Declarations}

\section{Ethics approval}

This study was approved by Isfahan University of Medical Sciences, Isfahan, Iran (IR.MUI.MED.REC.1399.677).

\section{Consent for publication}

All the authors of this manuscript announce their agreement to publish this study.

\section{Competing interest}

None

\section{Funding}

Not practicable

\section{Authors contribution}

All the authors of this work contributed in the design of this study.

\section{Acknowledgements}

The authors of this study wish to thank the Isfahan University of Medical Sciences, Isfahan, Iran for the financial support of this study. The authors also would like to thank Mrs. Farzaneh Haj Alikhani for her help to completion of this work.

\section{References}

1. Clarke M, Collins R, Darby S, Davies C, Elphinstone P, Evans E, Godwin J, Gray R, Hicks C, James S, Early Breast Cancer Trialists' Collaborative G. Effects of radiotherapy and of differences in the extent of surgery for early breast cancer on local recurrence and 15-year survival: an overview of the randomised trials. Lancet. 2005;366:2087-106.

2. Taylor CW, Kirby AM. Cardiac side-effects from breast cancer radiotherapy. Clin Oncol (R Coll Radiol). 2015;27:621-9.

3. Taylor C, Correa C, Duane FK, et al. Estimating the risks of breast cancer radiotherapy: Evidencefrom modern radiation dosestothe lungs and heart and from previous randomized trials. J Clin Oncol. 2017;35:1641-9.

4. Smith BD, Haffty BG, Wilson LD, Smith GL, Patel AN, Buchholz TA. The future of radiation oncology in the United States from 2010 to 2020 : will supply keep pace with demand? Journal of clinical oncology. 2010;28:5160-5.

5. Dessena M, Dessi M, Demontis B, Grosso L, Porru S, Meleddu G, Lay G, Murenu G, Amichetti M, Di Martino L. [Exclusive intra-operative radiation therapy (IORT) for early stage breast cancer: pilot study of feasibility]. II Giornale di chirurgia. 2011;32:104-9.

6. Tavakoli MB, Taheri H, Akhavan A. Measurement of ipsilateral lung and heart dose in radiotherapy of left sided mastectomy patients in common different clinical techniques: A phantom study. Int J Radiat Res. 2018;16(3):389-94.

7. Darby S, McGale P, Correa C, Taylor C, Arriagada R, Clarke M, et al. Effect of radiotherapy after breast-conserving surgery on 10-year recurrence and 15year breast cancer death: meta-analysis of individual patient data for 10,801 women in 17 randomised trials. Lancet. 2011;378:1707-16.

8. Clarke M, Collins R, Darby S, Davies C, Elphinstone P, Evans E, et al. Effects of radiotherapy and of differences in the extent of surgery for early breast cancer on local recurrence and 15-year survival: an overview of the randomised trials. Lancet. 2005;366:2087-106.

9. Edvardsson A, Nillson MP, Amptoulach S, Ceberg S. Comparison of doses and NTCP to risk organs with enhanced inspiration gating and free breathing for left-sided breast cancer radiotherapy using the AAA algorithm. Radiat Oncol. 2015;10:84.

10. Rudat V, Alaradi AA, Mohamed A, Khaled AY, Altuwaijri S. Tangenal beam IMRT versus tangenal beam 3DCRT of the chest wall in postmastectomy breast cancer patients: a dosimetric comparison. Radia + on Oncology. 2011;6:1.

11. Fong A, Bromley R, Beat M, Vien D, Dineley J, Morgan G. Dosimetric comparison of intensity modulated radiotherapy techniques and standard wedged tangents for whole breast radiotherapy. J Med Imaging Radiat Oncol. 2009;53(1):92-9.

12. Zablotska LB, Neugut Al. Lung carcinoma aQer radiaon therapy in women treated with lumpectomy or mastectomy for primary breast carcinoma. Cancer. 2003;97:1404-11.

13. Berrington de Gonzalez A, Curtis RE, Gilbert E, Berg CD, Smith SA, Stovall M, Ron E. Second solid cancers after radiotherapy for breast cancer in SEER cancer registries. Br J Cancer. 2010;102(1):220-6. 
14. Cuzick J, Stewart H, Rutqvist L, Houghton J, Edwards R, Redmond C, Peto R, Baum M, Fisher B, Host H, et al. Cause-specific mortality in long-term survivors of breast cancer who participated in trials of radiotherapy. J Clin Oncol. 1994;12(3):447-53.

15. Rutqvist LE, Lax I, Fornander T, Johansson H. Cardiovascular mortality in a randomized trial of adjuvant radiation therapy versus surgery alone in primary breast cancer. Int J Radiat Oncol Biol Phys. 1992;22(5):887-96.

16. Correa CR, Litt HI, Hwang WT, Ferrari VA, Solin LJ, Harris EE. Coronary artery findings after left-sided compared with right-sided radiation treatment for early-stage breast cancer. J Clin Oncol. 2007;25(21):3031-7.

17. Aznar MC, Korreman SS, Pedersen AN, Persson GF, Josipovic M, Specht L. Evaluation of dose to cardiac structures during breast irradiation. Br J Radiol. 2011;84:743-6.

18. Haddad P, Hadjilooei F, Nedaei HA, Kalaghchi B, Amouzgar HF, Farhan F, Babaei M, Esfahani M, Shahriarian Sh. Influence of different treatment planning techniques on radiation doses to the heart, left anterior descending coronary artery and left lung in the radiotherapy of left-sided breast cancer patients. Int J Radiat Res. 2019;17(1):119-25.

19. Zhang Q, Liu J, Ao N, Yu H, Peng Y, Ou L, Zhang S. Secondary cancer risk after radiation therapy for breast cancer with different radiotherapy techniques. 2020, 10:1220.

20. Gocer GPS, Ozer EE. Effect of radiotherapy on coronary arteries and heart in breast-conserving surgery: a dosimetric analysis. Radiol Oncol. 2020;54(1):128-34.

21. Warkentin B, Stavrev P, Stavreva N, Field C, Fallone BG. A TCPNTCP estimation module using DVHs and known radiobiological models and parameter sets. J Appl Clin Med Phys. 2004;5:5063.

22. Velázquez AA, Gutiérrez LP, González GR, Mitsoura E, Laguna AR, Castro JMF. Vázquez A P. TCP and NTCP Radiobiological Models: Conventional and Hypofractionated Treatments in Radiotherapy.

23. Lyman JT. Complication probability as assessed from dosevolume histograms. Radiat Res Suppl. 1985;8:139.

24. Taheri H, Tavakoli MB, Akhavan A. Radiobiological Evaluation of Three Common Clinical Radiotherapy Techniques Including Combined Photon-Electron, Tangential Beams and Electron Therapy in Left-Sided Mastectomy Patients. Adv Biomed Res. 2018;7:99.

25. Joiner M, Kogel A. Basic Clinical Radiobiology. 4th ed. London: Edward Arnold; 2009.

26. Niemierko A. A generalized concept of equivalent uniform dose (EUD). Med Phys. 1999;26:1100.

27. Baradaran-Ghahfarokhi M, Amouheidari A, Shahbazi-Gahrouei D, Baradaran-Ghahfarokhi HR, Tanderup K, Do" rr W, Shokrani P. Evaluation of the Effects of Prostate Radiation Therapy on Occludin Expression and Ultrasonography Characteristics of the Bladder. Int J Radiation Oncol Biol Phys. $2017 ; 4: 963-71$.

28. Taylor CW, Nisbet A, McGale P, Darby SC. Cardiac exposures in breast cancer radiotherapy: 1950s-1990s. Int J Radiation Oncol Biol Phys. 2007;69:148495.

29. Li J, Xiong W, Freedman GM, Anderson P, Ma C. Comparison of TCP and NTCP Between Conventional and Hypofractionated Breast Treatment. 46th Annual ASTRO Meeting. 